\title{
The Synthesis of a Natural Oligosaccharide Antibiotic Active Against Helicobacter pylori
}

\author{
Shino Manabe,* Kazuyuki Ishii, Yukishige Ito* \\ RIKEN (The Institute of Physical and Chemical Research) \\ Hirowasa, Wako, Saitama 351-0198, Japan \\ smanabe@riken.jp
}

\section{Supporting Information}

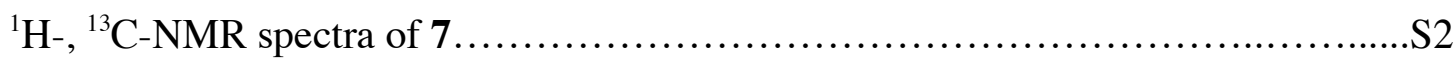

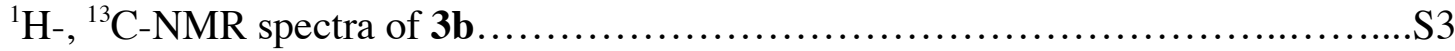

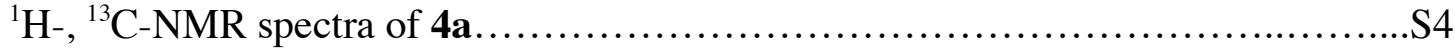

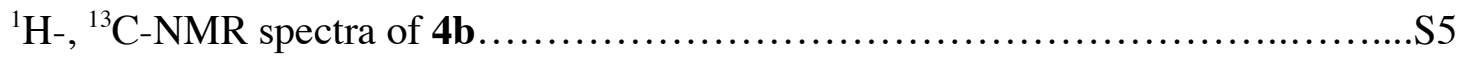

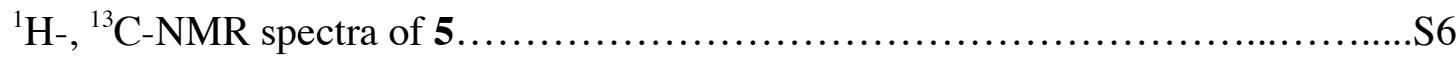

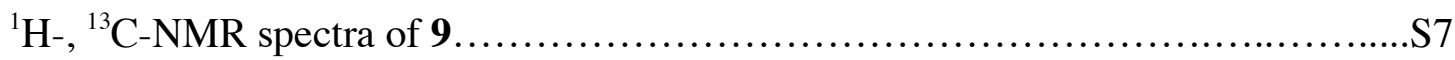

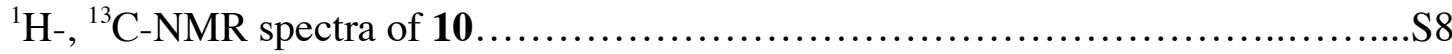

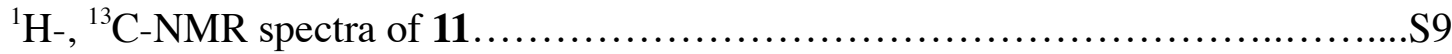

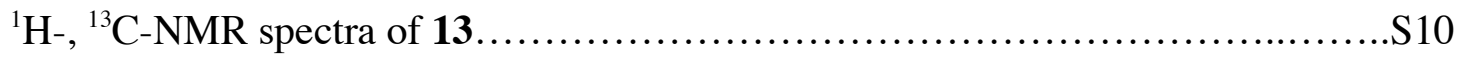

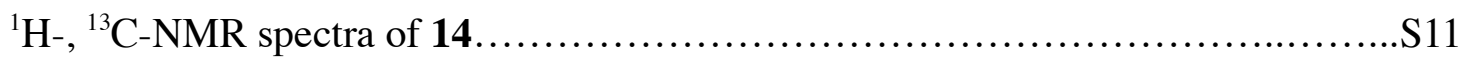

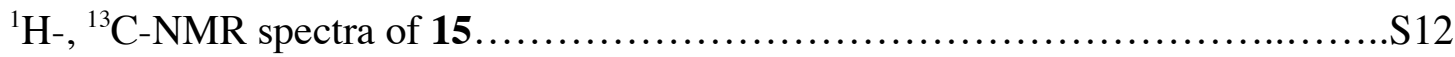

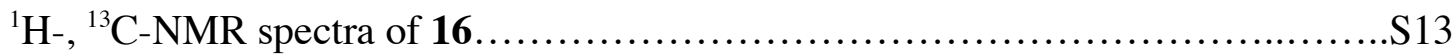

${ }^{1} \mathrm{H}-,{ }^{13} \mathrm{C}-\mathrm{NMR}$ spectra of deprotection intermediate.....................................S14

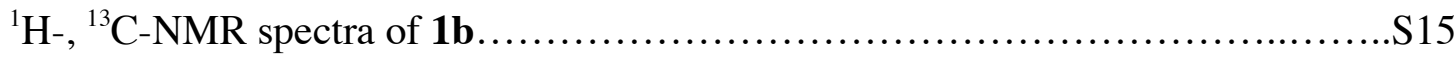



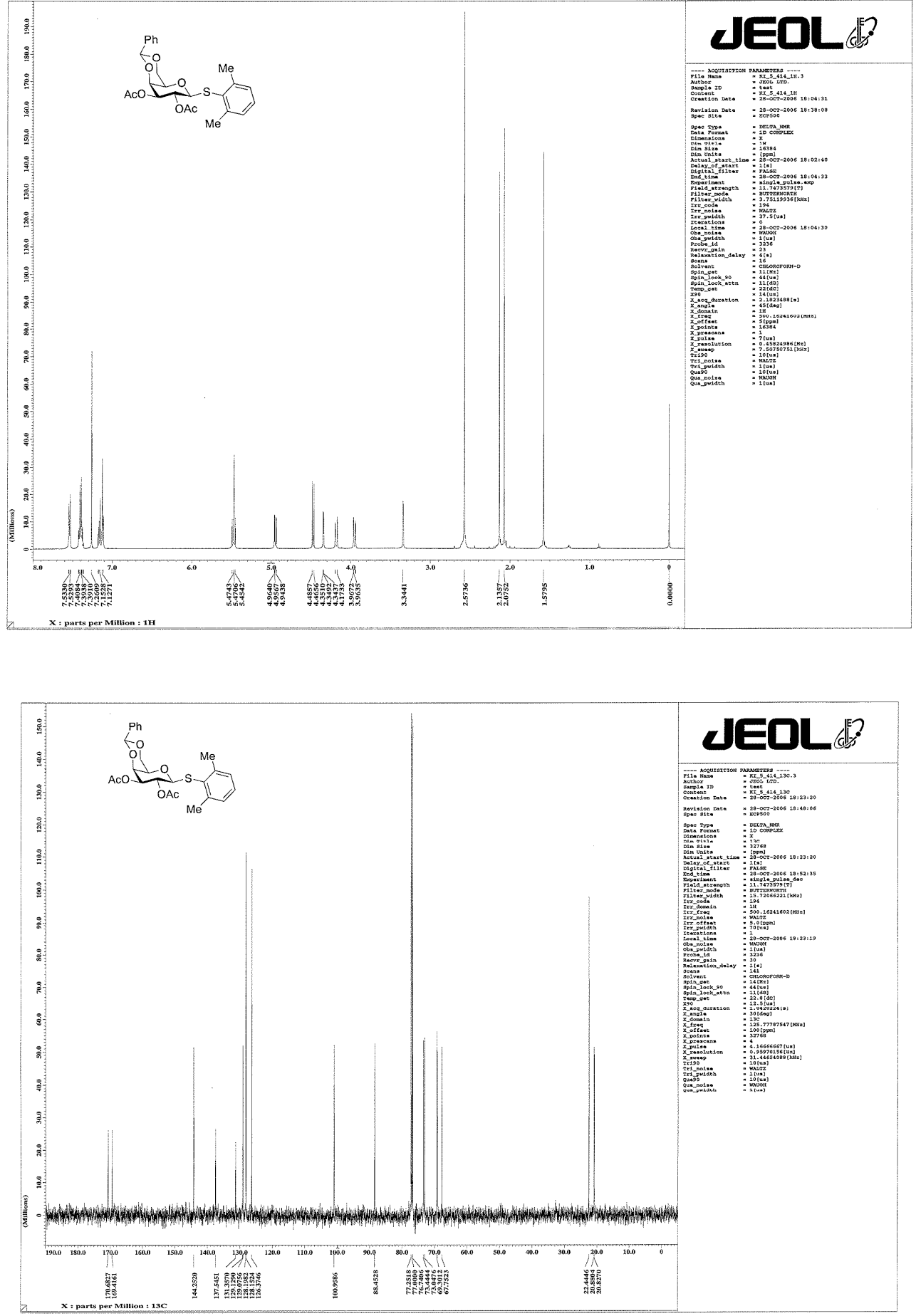
3b
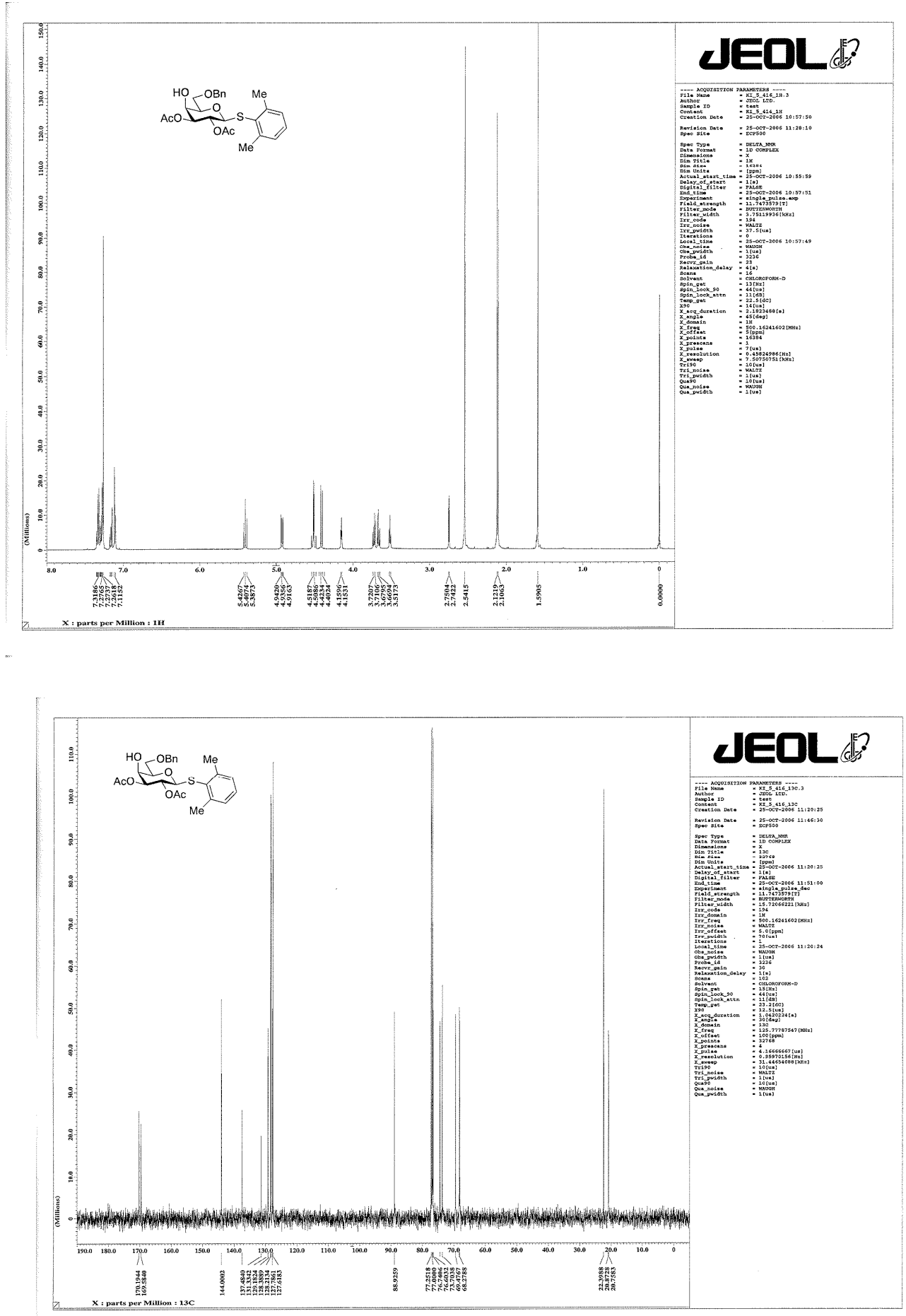
$4 a$
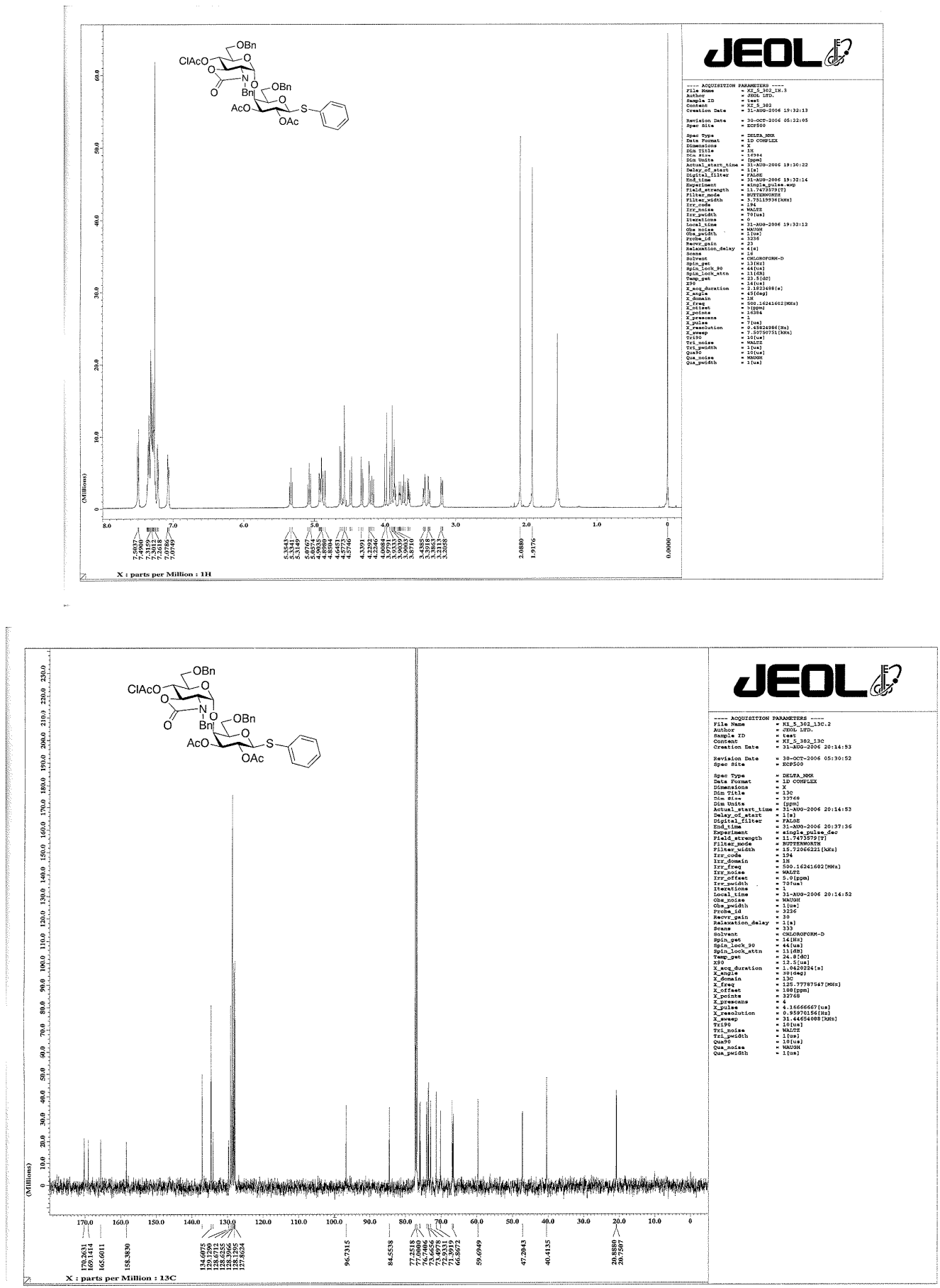
$4 b$
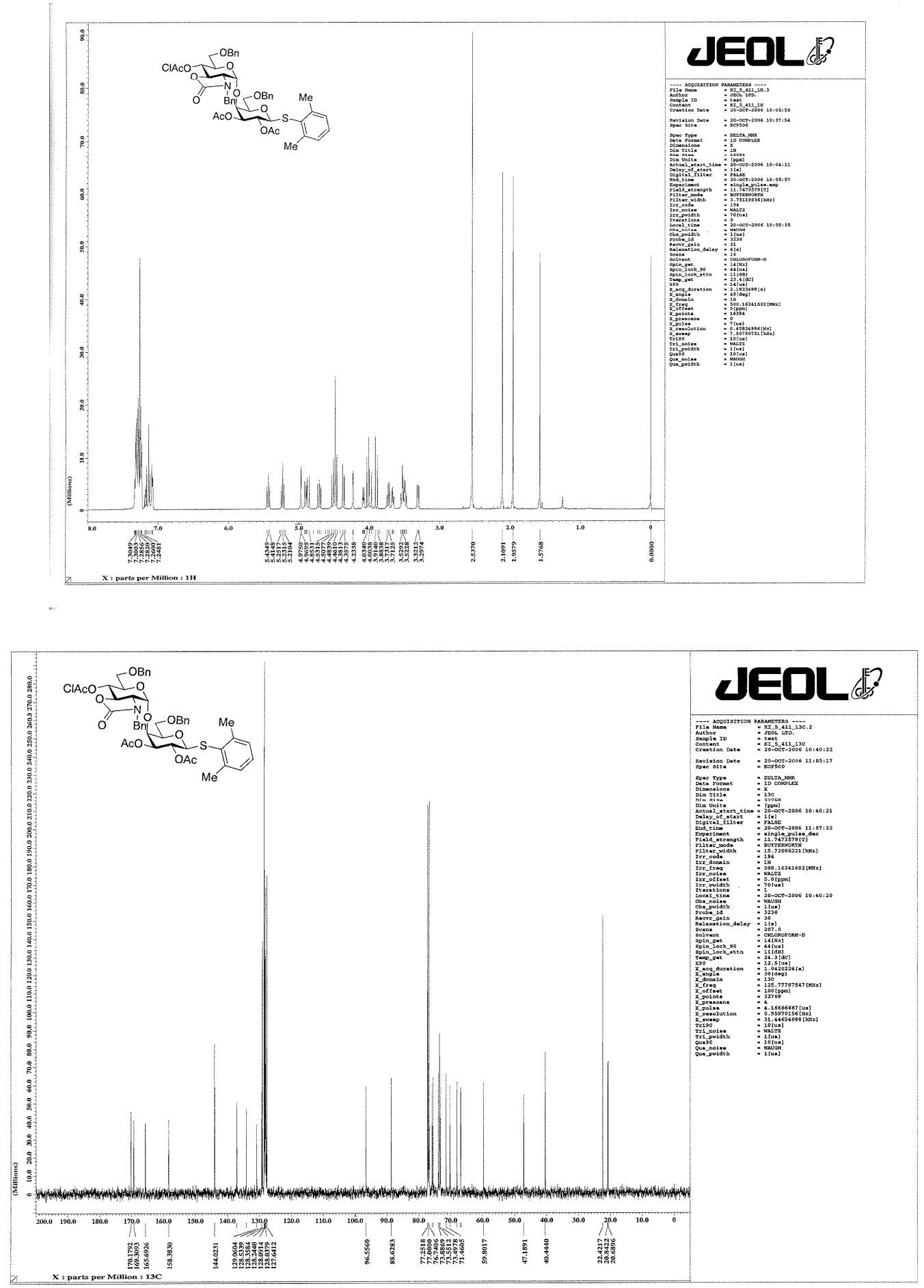

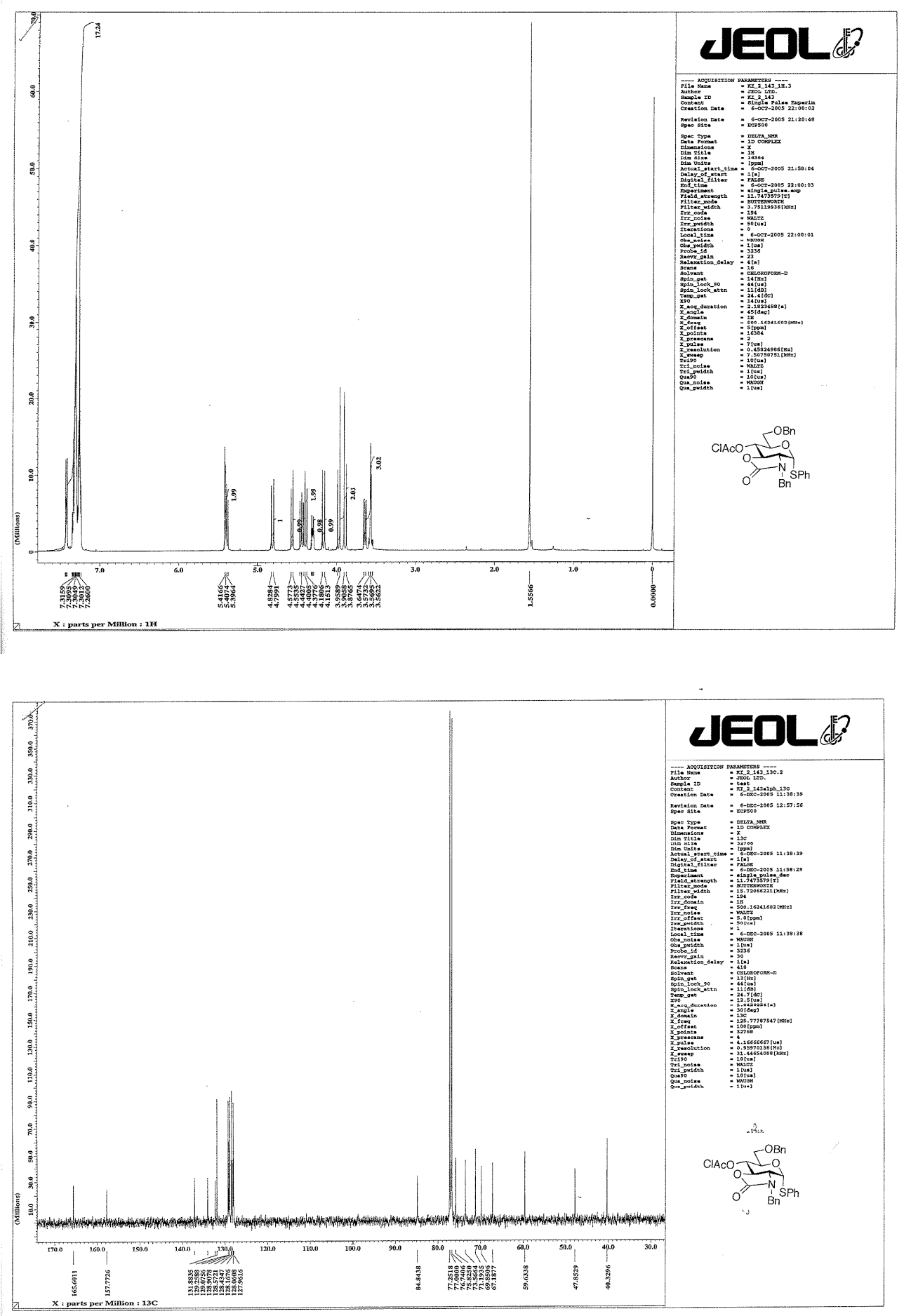

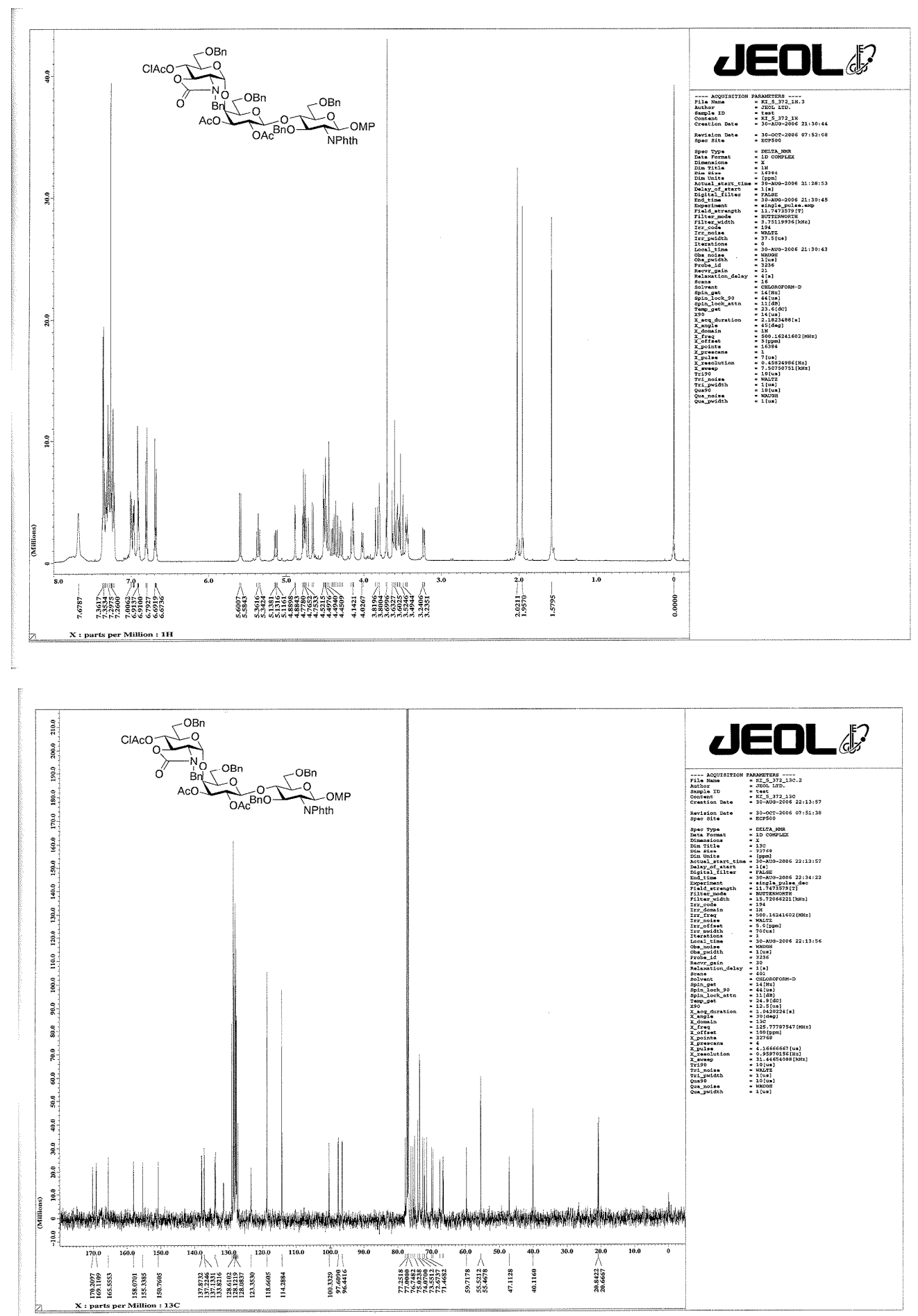


\section{0}
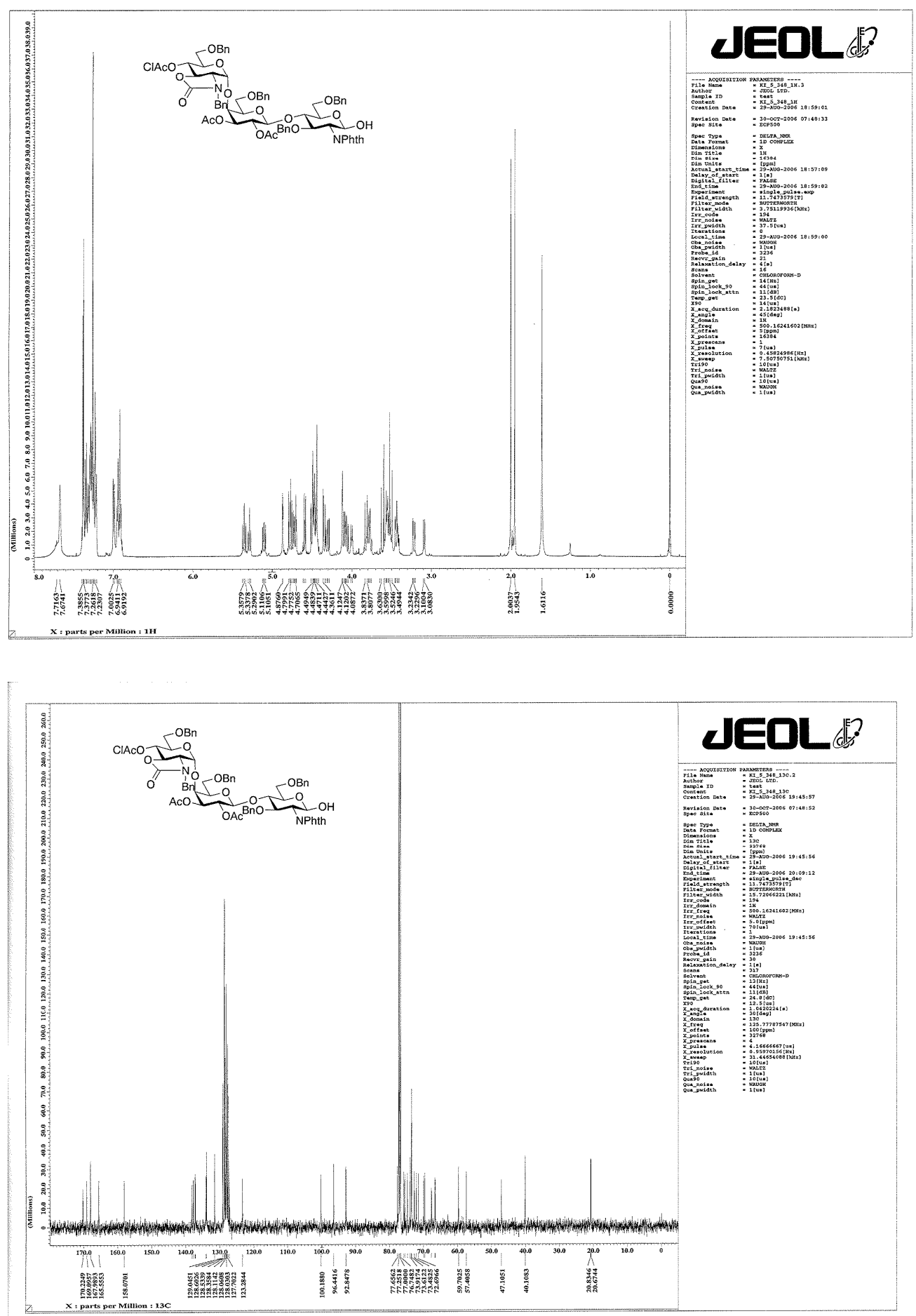

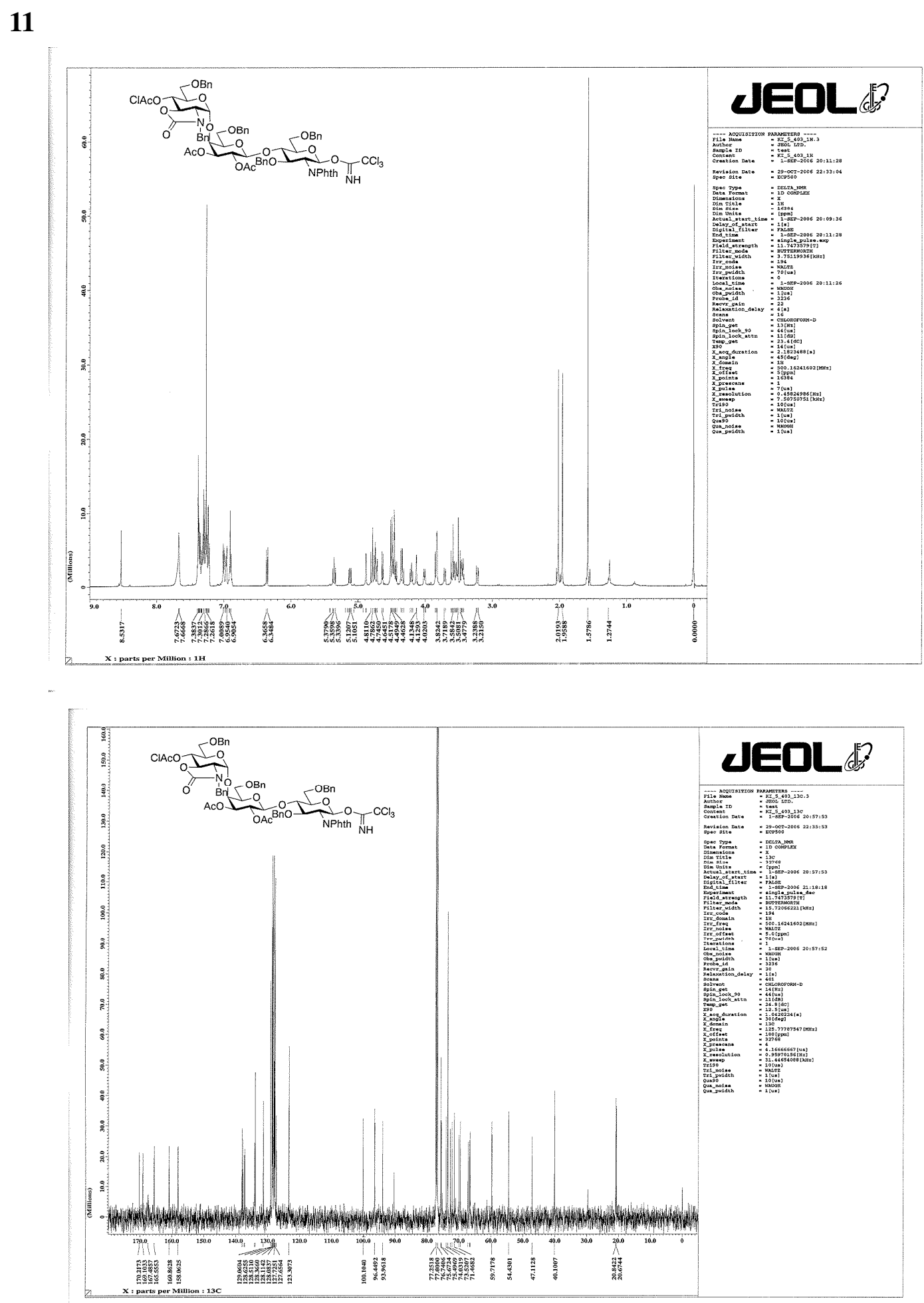
13
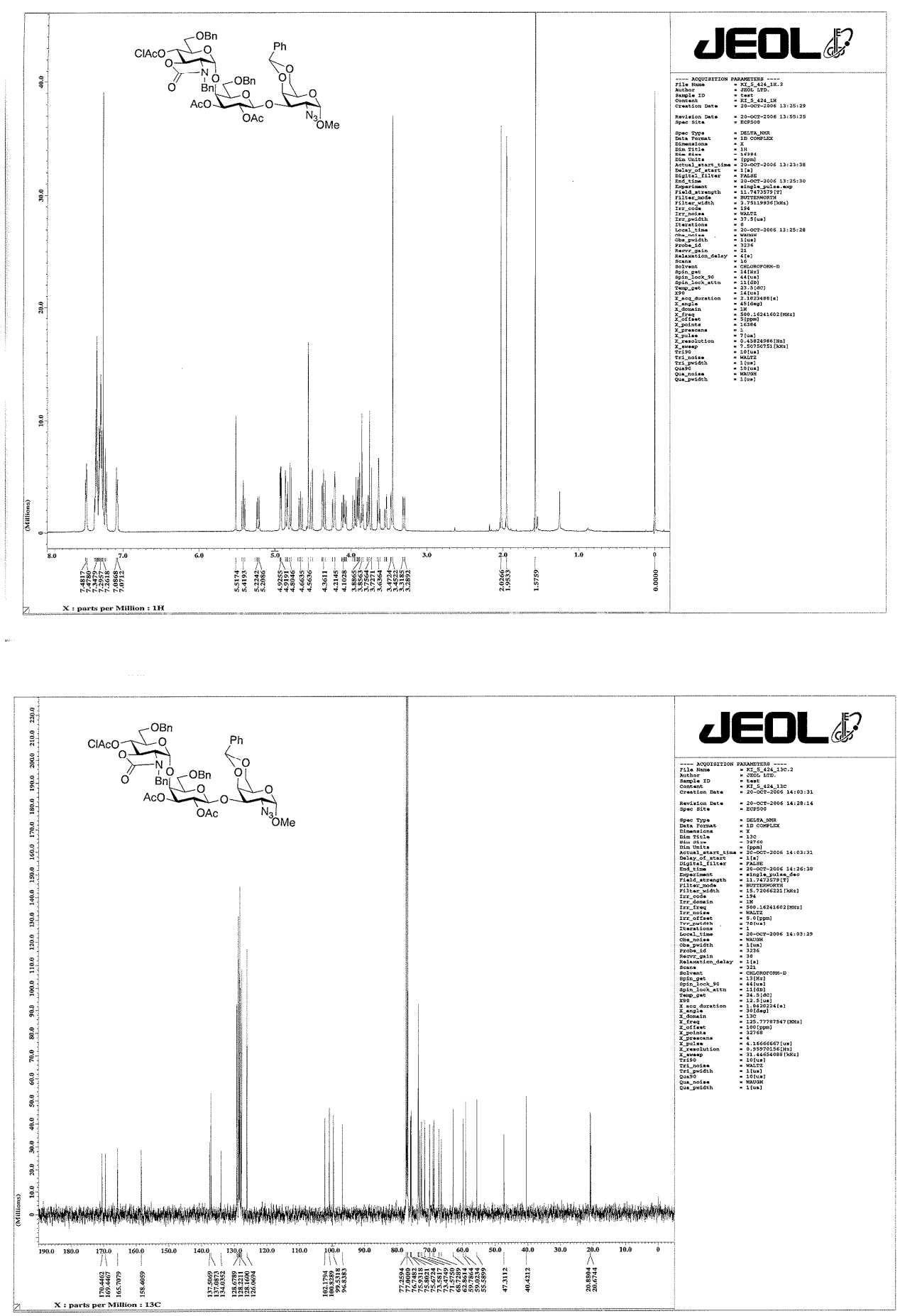


\section{4}
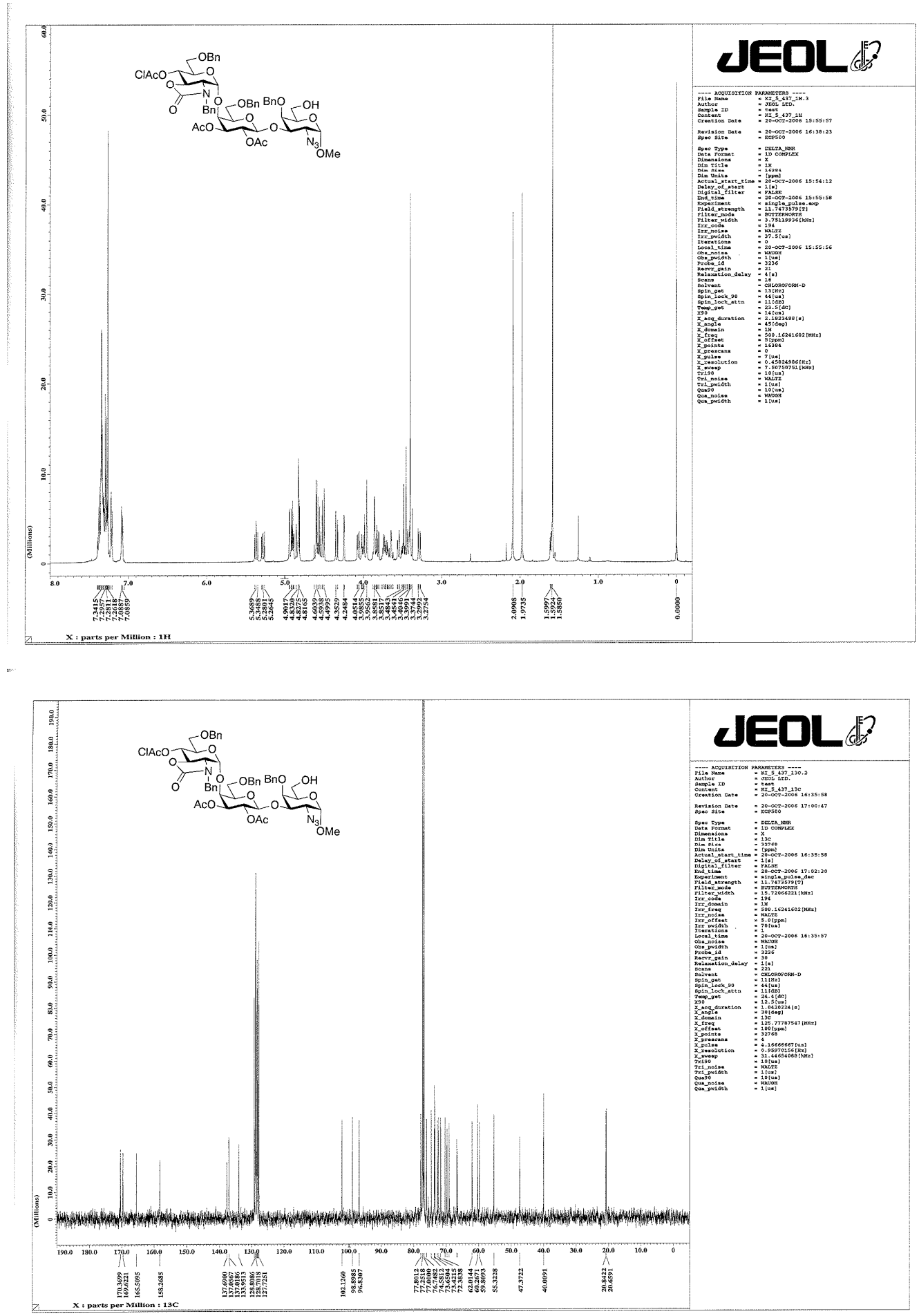


\section{5}
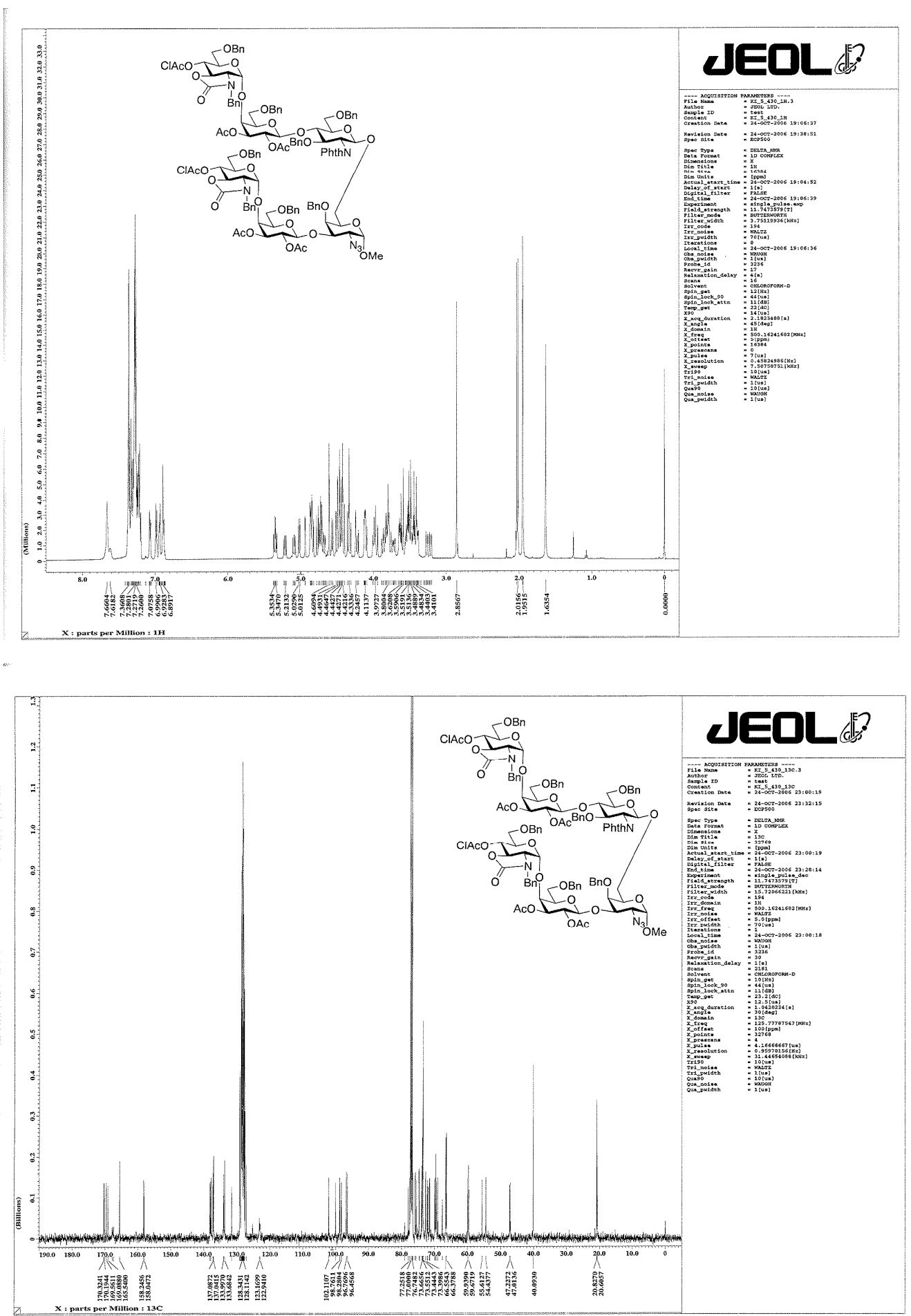

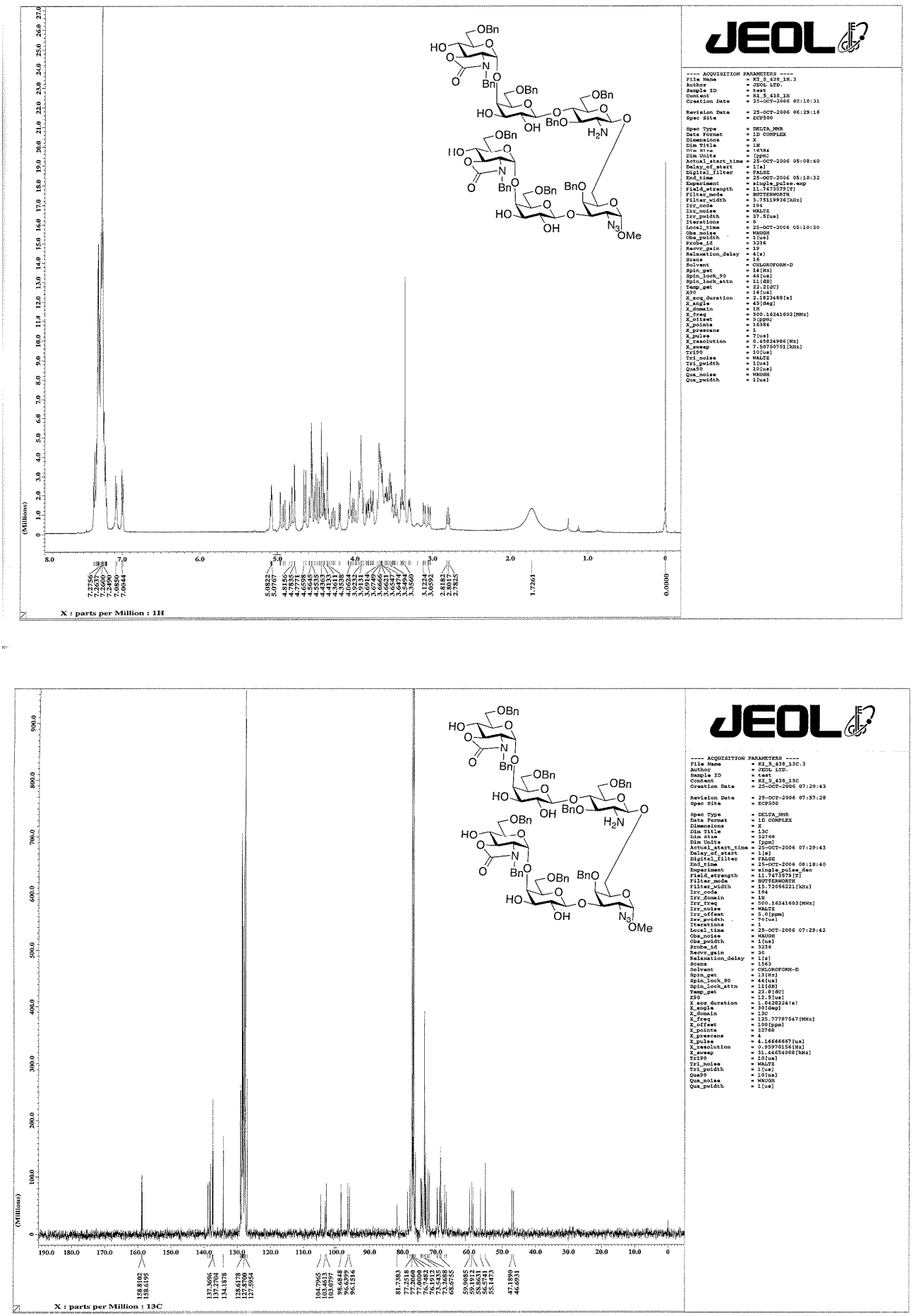

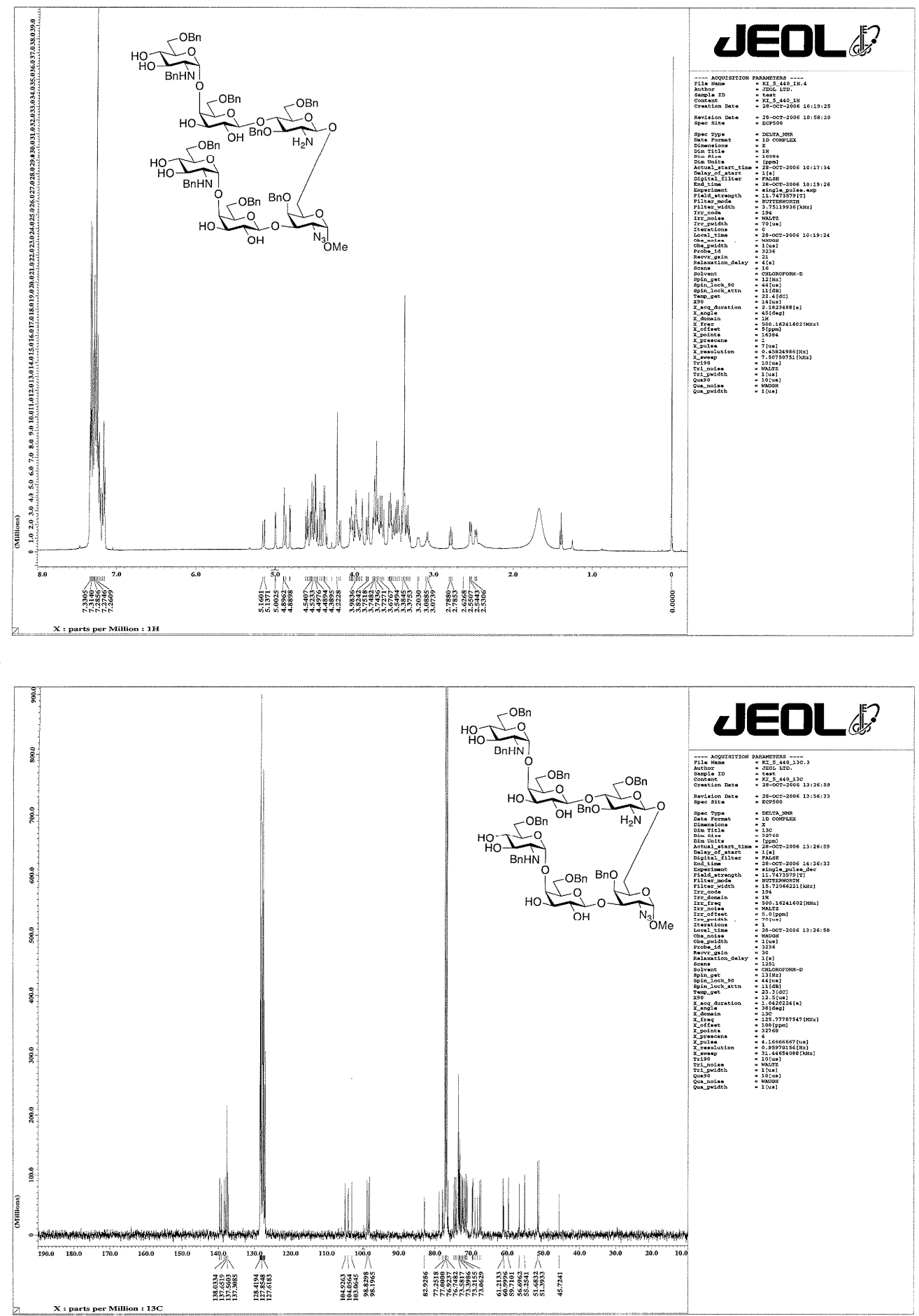

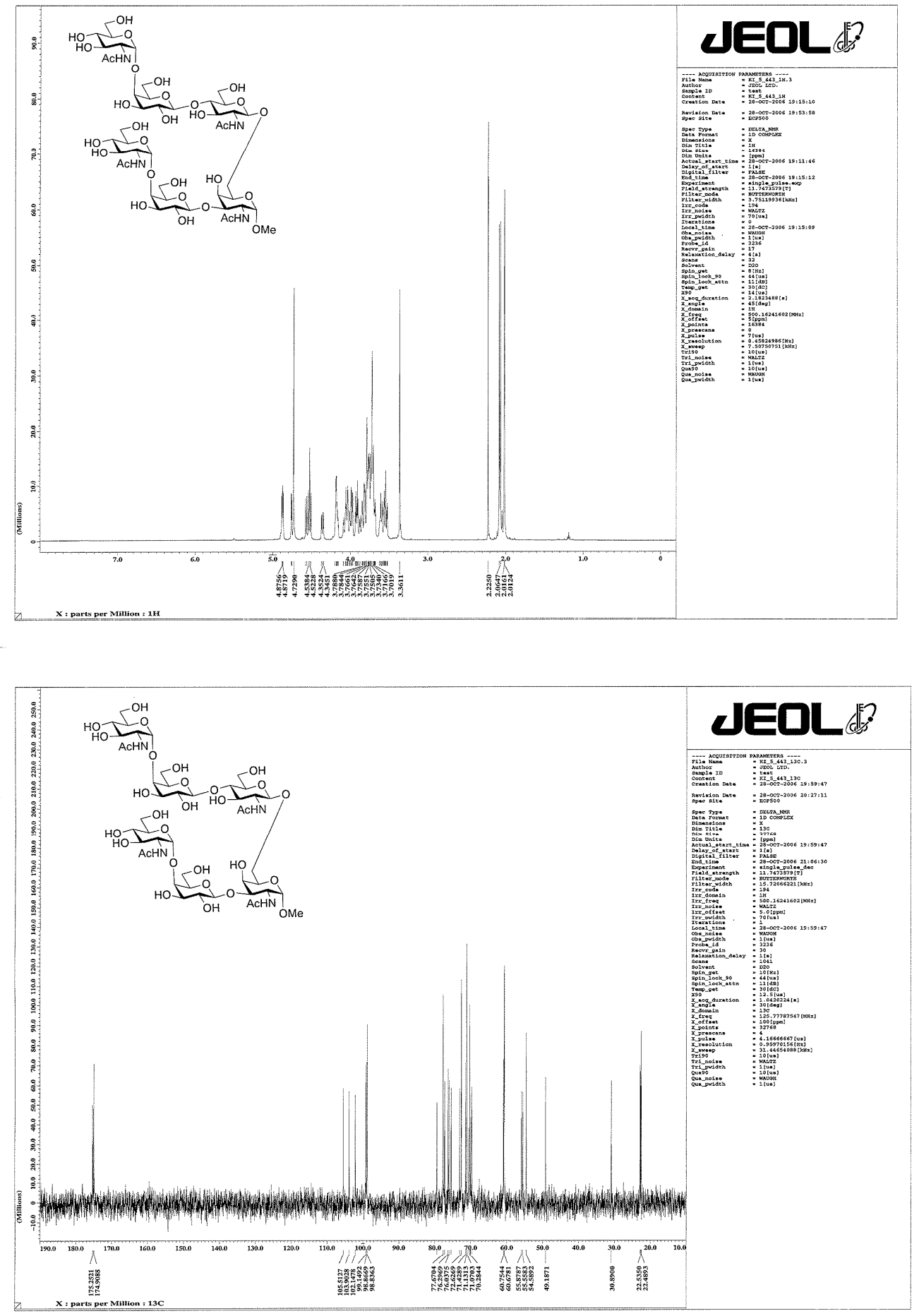